\title{
A new genus and species of neotropical Cercopidae (Tomaspidinae, Tomaspidini) ${ }^{1}$
}

\author{
Gervásio Silva Carvalho ${ }^{2}$ \\ Albino Morimasa Sakakibara ${ }^{3}$
}

\begin{abstract}
$A$ new genus and new species of spittlebug are described: Carachata dimorphica, gen.n., sp.n., from Itatiaia-RJ and Vilhena-RO, Brazil.
\end{abstract}

\section{Carachata gen. $\mathbf{n}$.}

(Figs. 1-10)

Type-species; $C$. dimorphica sp. $\mathrm{n}$.

Head triangular, its width 3 times the length of vertex, with two deep longitudinal impression on the vertex, surface smooth and shining. Tylus quadrangular, aproximately 1.5 times wider than long. Distance between ocelli 1.5 times its diameter, close to each other than to the eyes and posterior margin of head. Eyes ovate and transversal. Antennae with the pedicel visible from above, flagellum normal in length, with pyriform body and spiniform arista. Postclypeus, in the males, flatened in front, disk-shaped, the length aproximately 1.2 times the width, without carina, slightly concave, coarsely punctate, transversal sulcus weakly evident between the disk of posclypeus and gena; in the females, posclypeus tumid, almost normal, showing a feeble incomplete carina in direction to the anteclypeus, the length aproximately 1.4 times the width, transversal sulcus well marked and evident near antennae. Anteclypeus, in the males, flatened like posclypeus and in the same plan, clearly separated from it, punctured and with a small median elevation: in the females, the anteclypeus is not flatened, but with the same clear separation from the posclypeus. Rostrum ataining mesocoxae. Pronotum hexagonal, surface smooth; anterior and lateroanterior margins straight; latero-posterior and posterior slightly sinuated. Tegmina 3 times as long as wide, with the costal margin at the base slightly upturned and the anal margin more or less parallel; the veins distinct, $\mathbf{M}$ and $\mathbf{C u}$ united in the basal third. Wings with $\mathrm{Cu}_{1}$ not thickened at base. Hind tibiae with 2 lateral spines and a row of 10 apical spines; hind basitarsus with 9 apical spines in two irregular rows. Pygofer with a process on each side with blunt apex, situated between anal tube and subgenital plate; subgenital plate triangular;

1 Contribuição no 617 do Departamento de Zoologia da Universidade Federal do Paraná.

2 Institu to de Biociências da Pontifícia Universidade Católica do Rio Grande do Sul, C.P. 1429, 90000 Por to Alegre, RS, Brasil. Bolsista PICD/CAPES (Doutorado).

3 Departamento de Zoologia da Universidade Federal do Paraná. Bolsista do CNPq. 
aedeagus long, tapering and with processes; parameres slender, with a dorso-basal elevation well pronounced and the apical tooth directed outward. First valv of ovipositor with curved and lengthened process near the base.

Discussion: The representatives of this new genus differ from other 53 neotropical genera, in presenting the posclypeus flatened, laterally expanded in a disklike plate (only in the males). Similar characteristic is found in the Australian genus Haematoscarta Breddin but, on the other hand, it presents only one spine on the hind tibiae. In the neotropical Cercopidae there is no other genus with this kind of posclypeus. And also, by other characters, we put this new genus in Tomaspidini.

The generic name is feminine and composed by two Portuguese words related to the shape of the posclypeus of the male.

\section{Carachata dimorphica sp. $\mathbf{n}$.}

(Figs. 1-10)

Diagnostic character: color brown, with yellow patches; head with posclypeus flatened, as wide as the distance between eyes; pronotum smooth with a transverse yellow band on anterior margin: tegmina with three yellow stripes: one on the clavus extending to the midle, the second begining at costal margin on its anterior one third, obliquely to the half of the tegmina and, the last one, transversal at the apical third from costal to anal margin, including apex of clavus; thorax and legs yellow with darkened areas; abdomen blackish.

Mensurations (in mm): Holotype/Means of 8 males/Extent/Means of 4 females/Extent: Total length: 8.17/7 918/7.25-8.50/7 918/7.67-8.17; Length of tegminas: $6.58 / 6.439 / 5.83-692 / 6.383 / 6.17-6.58$; Greatest width of teminas: 2.10/2.055/1.90-2.18/2.020/1.94-2.10; Greatest width of pronotum: 2.32 / 2.275/1.98-2.44/2.290/2.20-2.34; Greatest width of head: 1.64/1.624/1.481.70/1.630/1.60-1.68: Interocular distance: $090 / 0.934 / 0.88-0.98 / 0.940 / 0.92$ 0.98; Width of tylus: $0.46 / 0.469 / 0.44-0.52 / 0.513 / 0.43-0.54$.

Types and type - locality: Holotype male: Itatiaia, Rio de Janeiro, 7.II. 1947, J.F. Zikan col. Paratypes: 1 male - Itatiaia, Rio de Janeiro, 22 XII.1937, J.F. Zikan col.; 7 males - Itatiaia, Rio de Janeiro, 850 m, I.1955, U. Barth col.; 1 male - Itatiaia, Rio de Janeiro, 950 m, I.1956, U. Barth col.; 1 male - Itatiaia, Rio de Janeiro, 2,000 m, I.1957, U. Barth - col.; 3 males - Vilhena, Rondônia, 27 XII.1986, C. Elias leg., Polonoroeste; 1 male - Vilhena, Rondônia, 4.XII. 1986, C. Elias leg., Polonoroeste; and, 4 females - Vilhena, Rondônia, 17 XII. 1986, C. Elias leg., Polonoroeste.

The holotype and 8 paratypes from Vilhena - RO are deposited in the Collection of Department of Zoology - UFPR. The remained paratypes: that collected by J.F. Zikan in Instituto Oswaldo Cruz - RJ and other 9 in Museu Nacional - RJ.

Description: Holotype male. Head 3 times as wide as length of vertex, color dull-brown; vertex smooth and shining, elevated longitudinal, in the midle, with two deep longitudinal impressions, begining at the posterior angle of tylus through posterior margin of head; supra-antennal ledge aproximately equal in width to tylus; ocelli normal, its diameter equal to 0.8 the distance bewteen 


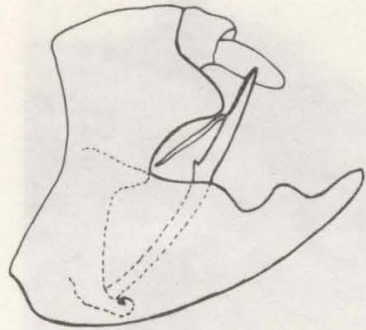

1
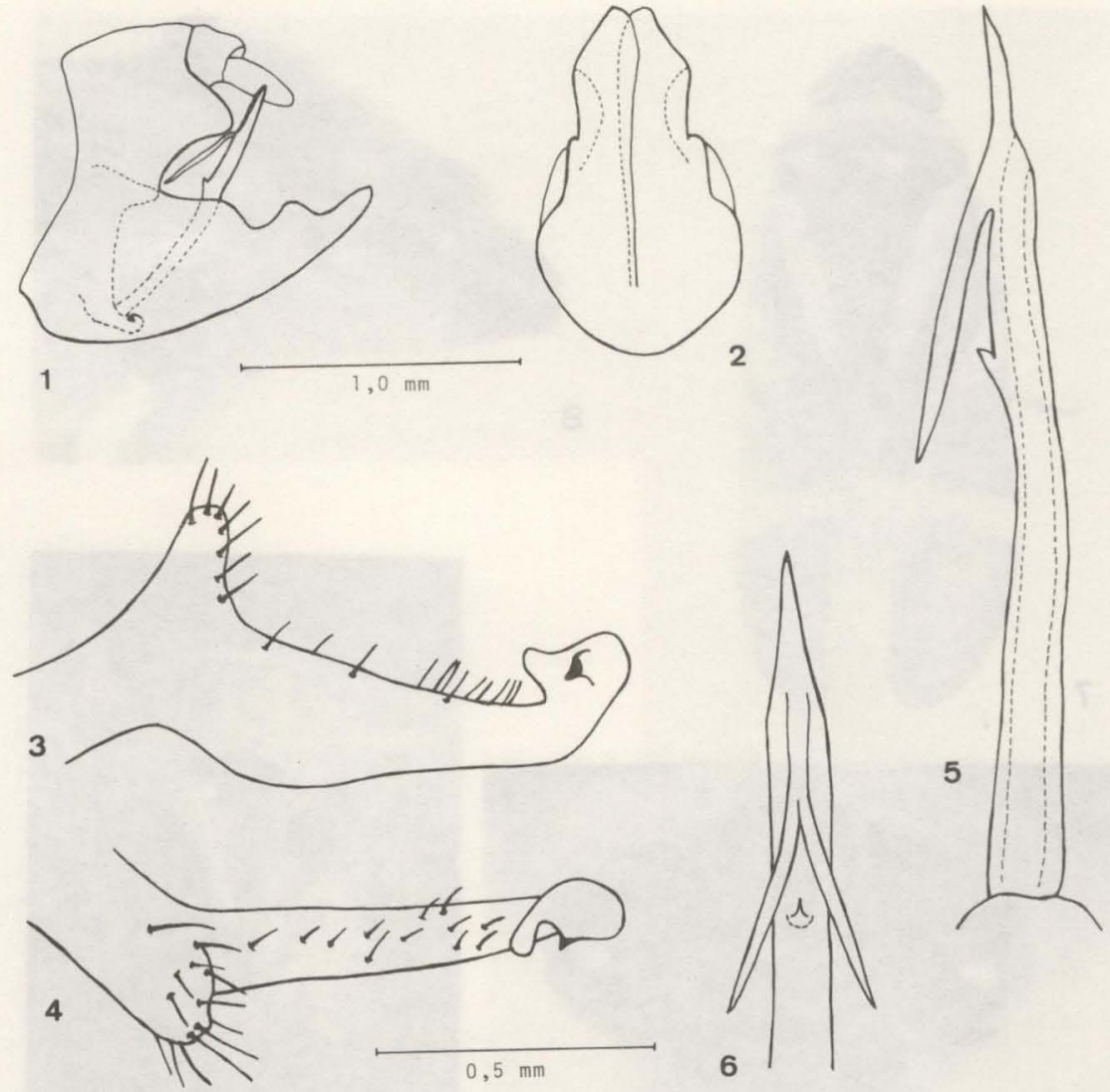

FIGS. 1 - 6-Carachata dimorphica gen.n.,sp.n. - 1, Lateral view of pygofer; 2, Inferior view of subgenital plates; 3, Lateral view of left paramere; 4, Dorsal view of left paramer; 5, Anterior view of aedeagus extremity; 6, Lateral view of left side of aedeagus. Scale in mm.

them, nearer each other than to the eyes and posterior margin of head; eyes ovate and transversal. Antennae dull-brown; scape seem from above, hiden by supra-antennal ledge; pedicel cylindric, the length 1.5 times longer than its diameter, partialy visible from above; flagellum with pyriform body; styles long and slender; spiniform arista, situated inferiorly and in the same plan of the style. Tylus quadrangular, wider than long, with median carina and, anteriorly, a small transversal pit. Postclypeus yellow, superior part dull-brown; lateraly expanded and strongly flatened, disk-shaped, without carina, slightly concave and coarsely punctured; transversal sulcus weak between margin of disk of postclypeus, two curved furrows begining near supra-antennal ledge. Antecly- 


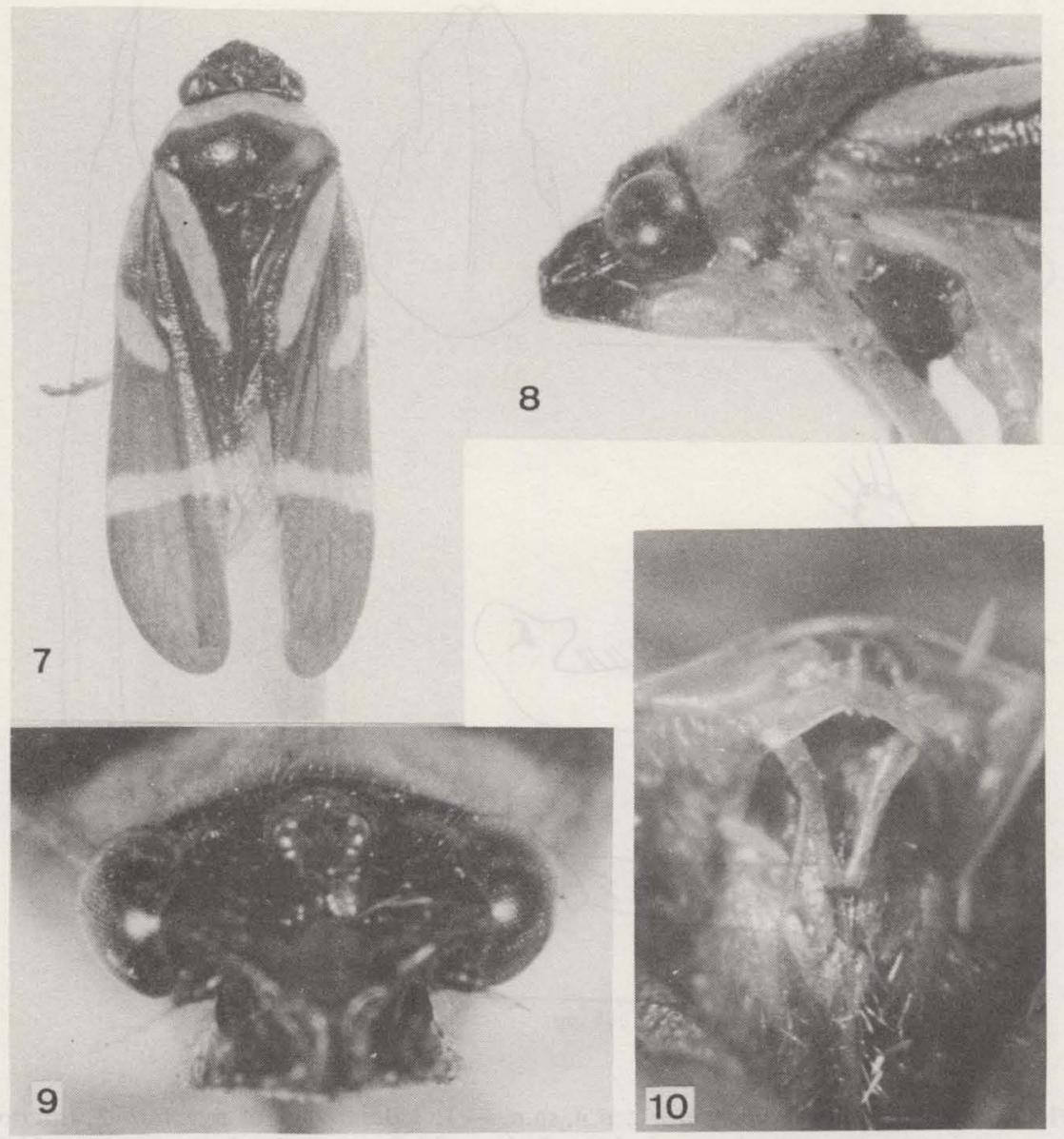

FIGS. 7 - 10 - Carachata dimorphica gen.n.,sp.n. - 7, Dorsal view; 8, Lateral view of head and pronotum; 9, Frontal view of head; 10, Ovipositor basal processes.

peus yellow, flatened, punctured, clearly separated from postclypeus and a small median elevation. Rostrum black, attaining mesocoxae. Pronotum dull-brown, a band on anterior margin, with $0.36 \mathrm{~mm}$ width, and edges of latero-anterior margins, yellow; punctured; decumbent pilosity, yellow; hexagonal; convex; median carina slightly marked, with a tiny impression on each side and two bigger muscular impression at level of the yellow band; latero anterior margins straight with a slightly furrow; latero-posterior and posterior margins more or less sinuated. Scutellum triangular, slightly longer than basal width, with depression and transversaly rugose; pilosity like that of pronotum. Tegmina 
brown, with same pilosity of pronotum; with three yellow stripes: the first on the clavus, longitudinal, starting at base through the midle, tapering, without touching anal margin; the second, more or less triangular, smaller, from costal margins to basal third, directed diagonaly to the midle of corium; the third, transversal, in the limit of the median and posterior third, from costal margim to clavus, near the tips; the length aproximately 3 times the width at extremity of clavus; veins distinct; $\mathbf{M}$ and $\mathbf{C u}$ united along the anterior third. Wings vitreous, veins well marked, with four apical cells; hamuliferous lobes triangular, with three hamuli; $\mathrm{Cu}_{1}$ not thickened near base. Legs yellowish, anterior and median tibiae, tarsus, blackish; posterior tibiae with two lateral spines, the basal one smaller, slightly bigger than the apical spines, these in numer of 10; posterior basitarsus with 9 apical spines, in two irregular rows. Thorax, beneath, yellow, median basisternum blackish. Abdomen blackish.

Genitalia. Pigofer dull-brown, with a latero-posterior tooth slightly curved downward; subgenital plate triangular with dorsal margin sinuated and blunt apex; parameres slender, basal-dorsal elevation well pronounced, apical tooth directed downward and outward, with an elevated and concave structure. Aedeagus cylindrical, more or less straight, at the level of anal tube, in front of foramen, straight and acute, two dorsal processes 2.6 times smaller than the aedeagus, tapering, pre-apical, divergent and basad and, underneth its insertion, a small median tooth.

Female: Identical to male, in general aspect; the posclypeus is tumid, with a feeble and incomplete median carina. Ovipositor basal processes curved backward, digitiform, 6.5 times longer than wide. 